\title{
LaSal, bar-biblioteca feminista en Barcelona. Empoderamiento femenino y cultura visual
}

\author{
Katia Almerini \\ Universidad Autónoma de Madrid
}

RESUMEN: El presente artículo pretende expandir la geografía de los espacios artísticos feministas de los setenta tratando el caso español de LaSal, bar-biblioteca feminista en Barcelona, donde tuvo lugar una búsqueda cultural y creativa en sintonía con las necesidades de renovación cultural del segundo feminismo. Después de la reconstrucción histórica del espacio, se analiza la promoción de una nueva producción visual, especialmente la ilustración y el cómic, donde las mujeres subvirtieron el estatuto que la sociedad les había conferido. La importancia del contexto específico posfranquista, con influencias del «feminismo de la diferencia» presente en las regiones mediterráneas, ofrece un ejemplo inédito, diferente de los modelos norteamericanos. El artículo, realizado gracias a un trabajo de campo, pretende asimismo proponer una reflexión renovada sobre el separatismo feminista de los setenta y evidenciar el específico aspecto de subversión que identifica LaSal como un posible espacio heterotópico.

PALABRAS CLAVE: Feminismo, Cultura visual, Barcelona, LaSal, Cómics, Heterotopía.

\section{LaSal, a Feminist Library-Bar in Barcelona. Feminine Empowerment and Visual Culture}

\begin{abstract}
The aim of this article is to expand the geography of feminist art spaces of the seventies through a close analysis of the Spanish case of LaSal. In this feminist library-bar in Barcelona, a creative search took place following the need for cultural reform of the second feminist movement. After a historic reconstruction of this space, this article will analyse the development of new visual production seen predominantly in illustrations and comics, where women subverted the status that society had given them. The significance of the post-Franco context within which this specific movement evolved, with influences of Difference Feminism from Mediterranean regions, lays on the fact that it offers an alternative to North-American models of feminist art spaces. Finally, the article, which has been elaborated in conjunction with original field research, proposes a renewed interpretation of separatist feminism throughout the seventies, and it highlights a specific aspect of subversion that identifies LaSal as a heterotopic space.
\end{abstract}

KEY WORDS: Feminism, Visual Culture, Barcelona, LaSal, Comics, Heterotopia.

Recibido: 10 de abril de 2014 / Aceptado: 30 de junio de 2014.

LaSal, bar-biblioteca feminista, abrió sus puertas el 6 de julio de 1977 en la calle Riereta número 8 de Barcelona. LaSal, uno de los primeros ejemplos de autogestión feminista y único espacio donde se dio cabida al arte hecho únicamente por mujeres, se caracterizó por ser una experiencia híbrida a medio camino en-

\footnotetext{
* ALMERINI, Katia: "LaSal, bar-biblioteca feminista en barcelona. Empoderamiento femenino y cultura visual", Boletín de Arte, n. ${ }^{\circ}$ 35, Departamento de Historia del Arte, Universidad de Málaga, 2014, pp. 83 100, ISSN: 0211-8483.
} 
tre el bar, el centro cultural y el espacio de reflexión feminista [1]. Nunca quiso seguir una línea feminista única, sino configurarse como un lugar de encuentro plural, acogiendo las diferentes posiciones del feminismo, tal y como se recoge en el documento fundacional' ${ }^{1}$. Desde el principio representó una experiencia fundamental para la evolución del movimiento feminista catalán y nacional en la España posfranquista de los setenta y un punto de encuentro para las mujeres españolas y extranjeras.

\section{Antecedentes históricos y sociales}

Para comprender completamente esta experiencia, es importante considerar la situación española de los setenta, donde la emancipación de las mujeres, en comparación con otros países occidentales, presenta una serie de peculiaridades. Asimismo es un deber reconocer la genealogía de los espacios femeninos y feministas en Cataluña, desconocida pero existente, que se compone tanto de lugares físicos como editoriales, que fueron el terreno histórico en que nació LaSal.

Antes del franquismo las mujeres habían vivido ya un importante momento de emancipación durante la II República (1931-1939), contribuyendo activamente a la creación de la democracia, de los partidos políticos y de las organizaciones sindicales. Como señala Elsa Plaza, participante de LaSal: "Con proyectos como estos, el del bar y las ediciones, se recobraba una tradición que el movimiento feminista, de finales del siglo XIX y comienzos del XX, había establecido con antelación, y que el olvido patriarcal y el franquista habían borrado de la memoria»². Si es verdad que las mujeres han vivido en los márgenes de la vida social, pública y artística, es cierto también que existieron múltiples ejemplos de mujeres, casos singulares y colectivos, prácticas culturales y artísticas que, a pesar de las dificultades, compusieron una trama de ejemplos olvidados pero significativos.

En el mismo barrio de LaSal, hoy el Raval, se habían vivido experiencias como la de Teresa Claramut, Amalia Domingo Soler y Ángeles López de Ayala, que habían fundado en 1889 la Societat Autònoma de Dones de Barcelona, que más tarde se convertiría en la Societat Progressiva Femenina, empeñada

1 LLINÁS CARMONA, Conxa, Feminismes de la Transició a Catalunya. Textos i materials, Barcelona, Horsori Editorial, 2008, pp.190-191.

2 Extracto de la ponencia de Elsa Plaza en la conferencia «En torno a genealogías feministas en el arte español: 1960-2010" organizada en Madrid en el Museo Nacional Centro de Arte Reina Sofía el 22 de febrero de 2013 (Mesa: Cultura y Feminismo años setenta). 


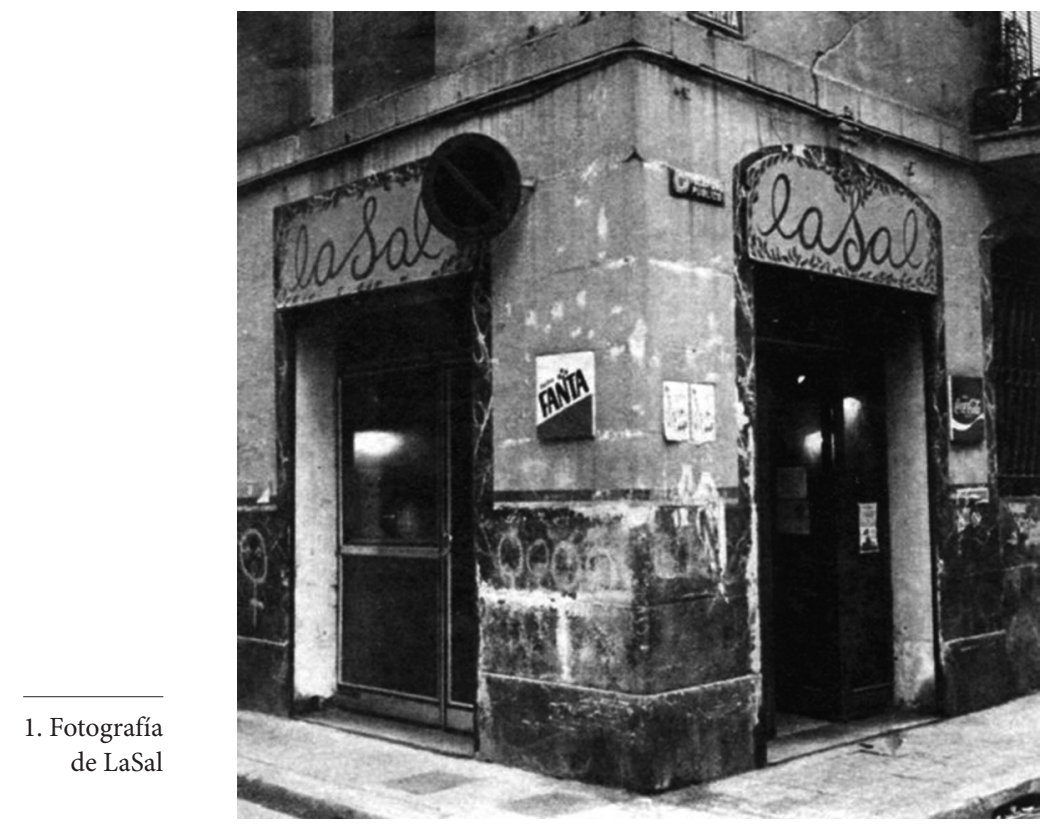

en facilitar instrucción laica a las trabajadoras. En la misma zona, también se encontraba el grupo de Las Malthusianas del Grupo Salud y Fuerza que tenía su sede en la calle de la Junta de Comerç hacia el año 1908. En esos años ya circulaban revistas feministas como Feminal de 1907, fundada por Carmen Karr o El Gladiator, que conectaban con el feminismo europeo, dando visibilidad al movimiento sufragista. En 1909 Francesca Bonnemaison fundó el Institut de Cultura i Biblioteca Popular per a la Dona, primera biblioteca europea dirigida a las mujeres ${ }^{3}$. En la época republicana hubo muchas mujeres que lucharon por el voto y por mejorar la condición de la mujer: en 1934 se formó la Unió de Dones de Catalunya, un órgano unitario de lucha que trabajaba sobre las situación de la mujer y el Grupo Cultural Femenino. Con esta red de asociaciones, las mujeres habían empezado a cambiar el estatus pasivo que la sociedad les había conferido desde hacía siglos.

Llegando al franquismo, esta red enérgica, propulsora de un cambio continuo de la sociedad, será destruida y ocultada. El nuevo estatus de la mujer debía respetar las exigencias del régimen: adecuarse a un modelo artificial y abstracto

3 LLINÁS, Feminismes de la Transició..., p. 19. 
creado por el fascismo e impuesto por Franco, un modelo que tenía que respetar el arquetipo de "la casada perfecta, prolífica y casta, pudorosa y altruista que no podía tener un proyecto propio de vida» ${ }^{4}$.

La muerte de Franco en 1975 y el comienzo de la Transición, coinciden con el estallido del segundo feminismo, aunque con el intento de avanzar a través de un pacto social por la paz y la estabilidad, se siguió alimentando la interrupción del relato histórico que, con el tiempo, generó una vacío en la memoria, dejando caer en el olvido las conquistas sociales precedentes al periodo dictatorial. Con el segundo feminismo, se alcanzan nuevas metas a nivel internacional, fundamentalmente: salir del aislamiento íntimo y social, trabajar sobre la autoestima, sobre los derechos a la salud, conquistar el control de la propia sexualidad, de la maternidad, luchar por el derecho al divorcio y al aborto y reflexionar sobre el lenguaje y los condicionamientos culturales. Aun así, las mujeres en España, que habían sufrido la dictadura, tenían que luchar también por los derechos básicos que el franquismo había borrado, determinando una fuerte vinculación del movimiento a la lucha política por la democracia. Unos meses después de la muerte de Franco se organizaron las I Jornadas de Liberación de la Mujer, celebradas ilegalmente en Madrid desde el 6 al 8 de diciembre.

Las Jornadas, donde emergieron las diferentes líneas del feminismo ${ }^{5}$, podrían considerarse como el comienzo de la visibilización del movimiento feminista español, que se caracteriza por la práctica social, política y personal de la relación. Estar en relación significó salir del aislamiento que la sociedad imponía a las mujeres, salir fuera de las paredes domésticas y encontrarse en espacios reales ya que no existían lugares ni en el mundo laboral, ni de diversión, donde tuvieran acceso las mujeres. Salir por primera vez de la íntima alienación personal, familiar, emocional y psicológica es lo que generó el eslogan lo personal es político, un momento que marca el paso de lo individual a lo colectivo. Ese proceso de extroversión, empezar a relacionarse, comenzó en muchos casos

4 ALEMANY, Joaquima, Dones, els camins de la llibertat, Museu d'Història de Catalunya (MHC), exposición 17 abril-20 julio 2008, Barcelona, 2008, p. 156.

5 La situación política y la necesidad de un proceso completo hacia la democracia dan lugar a tres líneas principales de activismo, que emergen ya en estas primeras jornadas: la primera, optar por la lucha general, postura de la vía política o corriente socialista; la segunda, optar por la lucha feminista única, era la corriente radical, que considera el feminismo como una opción global (representada sobre todo por colectivos feministas); y una tercera vía, intermedia, que no quería vincularse con los partidos aunque admitía la doble militancia. La tercera corriente, sobre todo representada por las catalanas, consideraba que no se podía cambiar la situación de la mujer sin un cambio radical en la estructura social, hacia una sociedad socialista. Pensaban que esto no revolucionaría la situación femenina y por eso era necesario mantenerse independientes. También surgió la línea radical materialista apoyada por Lidia Falcón y Cristina Alberdi, que proponían el nacimiento de un Partido Feminista, que efectivamente se creará en 1979. 
de forma espontánea y a través de reuniones informales de grupos de amigas, que necesitaban compartir su malestar y que no encontraban, en las opciones existentes, canales ni maneras para manifestarlo6. En 1976 se organizaran las I Jornades Catalanes de la Dona en Barcelona, que supusieron «la consolidación definitiva del feminismo catalán como gran movimiento social de la Transición ${ }^{7}$. Bajo la línea promovida por las catalanas, habían nacido diferentes grupos en todo el país como por ejemplo LA MAR (Lucha Antiautoritaria de Mujeres Antipatriarcales Revolucionarias) en Barcelona, o el Seminario Colectivos de Madrid y otros en diferentes ciudades que se concretaron en el Frente de Liberación de la Mujer ${ }^{8}$. La participación masiva, más de 4.000 personas, dio relevancia a la cuestión feminista en los medios de comunicación y en la política, contribuyendo sustancialmente a la apertura de un debate general en la sociedad sobre la cuestión de la mujer. La prensa juzgó duramente los encuentros cargando de negatividad la misma esencia del feminismo, actitud que nos ayuda a entender por qué muchas artistas, aunque incluían ya en sus obras temáticas de género y eran militantes, rechazaban una adhesión explícita al movimiento, teniendo miedo de todos los adjetivos excluyentes ligados a la imagen social de las activistas, en la que iba produciéndose una descalificación genérica social de las feministas ${ }^{9}$.

En Barcelona la red de espacios utilizados para reuniones, encuentros sindicales, grupos de self-help sexual, es muy densa y empieza la "autoconciencia". Practicada tanto en EE. UU. y sobre todo en Italia, esa práctica es una de las experiencias fundamentales para el desarrollo del movimiento. Como nos informa Conxa Llinás Carmona ${ }^{10}$, se conocían algunos textos extranjeros en Barcelona que teorizaban esta práctica, como el libro Escupamos sobre Hegel de Carla Lonzi y Autocoscienza de Simona Martinella, publicados en 1975 por Rivolta Femminile $^{11}$. La autoconciencia, experiencia que "se hace y no se traduce» ${ }^{12}$, representa

6 ESCARIO, Pilar; ALBERDI, Inés; LÓPEZ-ACCOTTO, Ana Inés, Lo personal es político. El movimiento feminista en la Transición, Madrid, Instituto de la Mujer-Ministerio de Asuntos Sociales, 1996, p. 56.

7 ALEMANY, Dones, els camins..., p. 161.

8 Para profundizar en el tema de las agrupaciones políticas véase MORENO Amparo, Mujeres en lucha. El movimiento feminista en España, Barcelona, Anagrama, 1977.

9 ESCARIO, ALBERDI, LÓPEZ-ACCOTTO, Lo personal es..., p. 65.

10 "A començament dels anys setenta, moltes vegades per viatges o per contactes amb dones d'altres països, es van estendre, per Catalunya y també arreu de l'Estat espanyol, els anomenats grups d'autoconsciència». ("A principios de los años setenta, muchas veces a través de viajes o de contactos con mujeres de otros países, se extendieron por Cataluña, y también por todo el Estado español, los denominados grupos de autoconciencia»), LLINÁS, Feminismes de la..., p. 27.

11 El grupo italiano feminista y la editorial Rivolta Femminile fueron fundados por Carla Lonzi, Carla Accardi y Elvira Banotti en 1970.

12 BERTILOTTI, Teresa, SCATTIGNO, Anna, Il femminismo degli anni Settanta, Roma, Viella, 2005, p. VIII. 
en España, como en otros países, un momento necesario: la posibilidad de liberarse, escapar de los tabúes, compartir miedos, a través de una modalidad similar al psicoanálisis, dejando fluir libremente la palabra y las experiencias más íntimas, a través del predominio del discurso oral. Estas experiencias servirán para construir una reflexión y una toma de conciencia sobre qué significaba ser mujer en una sociedad patriarcal, empezar a reconocer los mecanismos de poder del sistema social y familiar con un trabajo personal a veces muy doloroso que las cambió para siempre.

\section{El surgimiento de LaSal, espacio feminista}

En este contexto denso de debates, encuentros, protestas y a raíz de las Primeres Jornades Catalanes, nace el espacio LaSal, bar-biblioteca feminista en Barcelona. Así como pasó en diferentes países, tras una primera fase del segundo feminismo (sobre todo de vuelta a la liberación y al autoanálisis), surgió la necesidad de actuar en la sociedad, de disponer de un espacio, de información y de una plataforma de acción ${ }^{13}$. Las fundadoras de LaSal fueron María José Quevedo, Sat Sabater, Montse Solà, Carme Cases y Mari Chordà. Las mujeres Ilegaban del activismo político, la resistencia y el exilio, muchas de ellas habían vivido en Francia, especialmente París. Después de las dudas iniciales y complicaciones sobre la modalidad de gestión, la opción decidida fue la co-propiedad, aprovechando el espacio de lo que era la antigua taberna Alberto. Dentro de la programación cultural hubo también exposiciones de artistas, cuyas obras mostraban contenidos de género, crítica al sistema patriarcal o que simplemente se expusieron, puesto que el acceso al sistema del arte resultaba más complicado. Entre las artistas que pasaron por el espacio, se recuerdan entre otras: Eugènia Balcells, que proyectó el vídeo Boy meets Girl, Elsa Plaza, Virginia Poggi, Monserrat Clavé. Hubo también una significativa producción de material visual como calendarios, pósteres de encuentros, agenda de las mujeres, portadas de revistas, portadas de libros y cómics. En 1978 nació la editorial, LaSal, Edicions de les Dones, enfrente del espacio del bar-librería, en el número 13 [2]. Fue fundada por Mari Chordà, Mariló Fernández, Isabel Martínez e Isabel Monteagudo. Más tarde se unieron María Bauçà, Mireia Bofill, María José Quevedo, Carme Cases, Montserrat AbeIló, Mercè Fernández, Isabel Segura, Goya Vivas y Eugenia Curto [3]. La editorial 
2. Elsa Plaza, dibujo para LaSal, Edicions de les Dones

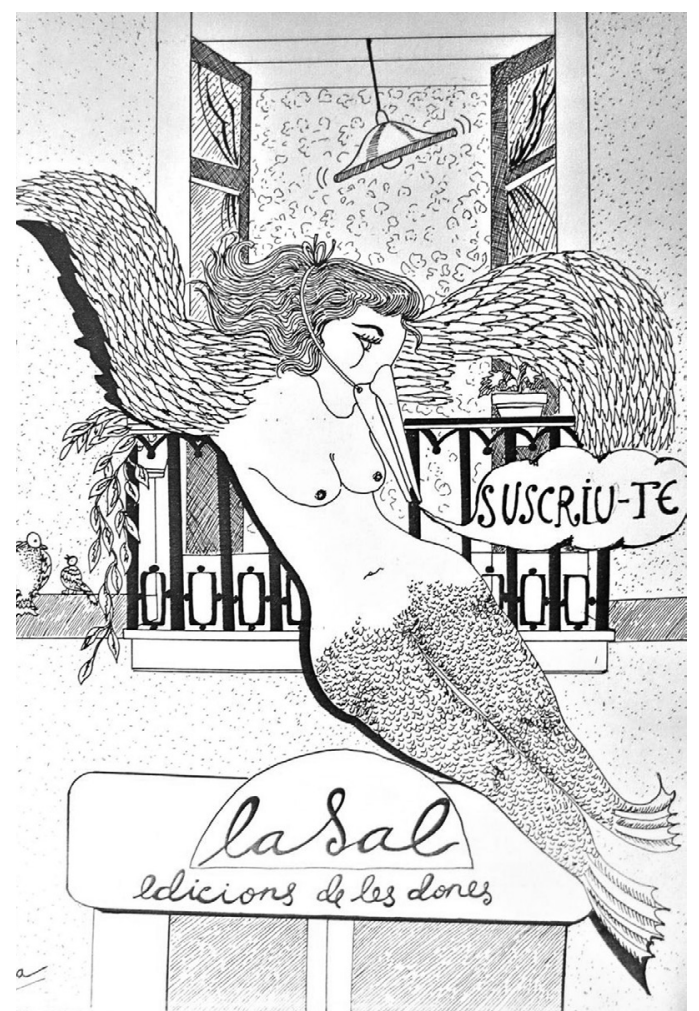




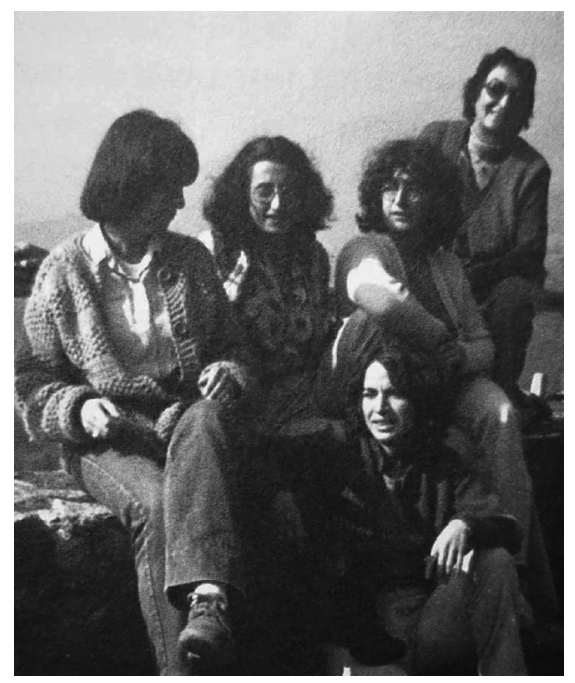

3. Fotografía del colectivo LaSal, Edicions de les Dones, 1980

toria, ironía y arte, además de citas y promoción de artistas. Las portadas de los libros y las agendas de la mujer contaron con la colaboración de varias artistas.

La programación de las actividades en LaSal fue muy diversa. Los martes se organizaban talleres y seminarios de diferentes disciplinas: de expresión corporal de Esther Bonet, de antropología de Marta Moia y Rita Prieto, de pintura, de astrología, de mecánica para coches, hecho con Maite Aizpurua, de costura rápida impartido por Carme Cases y hubo un seminario sobre Virginia Woolf, organizado por Marta Pessarrodona. Se organizaron eventos literarios, presentaciones de libros como: Mujeres, de Marilyn French; La pequeña diferencia y sus grandes consecuencias, de Alice Schearzer; Mujeres de España (las silenciadas), de Antonina Rodrigo, presentada por las autoras Federica Montseny y Montserrat Roig ${ }^{15}$, que supuso un gran éxito por la vuelta de Montseny del exilio. También hubo performances, conciertos de música, Txiky cantó varias veces con Anna Subirana y Teresa, la "Titi», que tocaba las percusiones. Hubo espectáculos de teatro, como por ejemplo, La dulce vida con Dolça Vilallonga y el Teatrí de les Dones o los recitales de música del grupo La Traca.

LaSal fue un espacio que hoy llamaríamos polivalente, un híbrido entre el bar, el espacio artístico, cultural y político y donde se celebraban también debates sobre las cuestiones más sensibles para las feministas como la autogestión,

15 CHORDÀ, Mari, "La Sal, bar-biblioteca feminista de Barcelona» en ALEMANY, Dones, els camins..., p. 178. 
4. Portada de la Agenda de la Mujer 1979

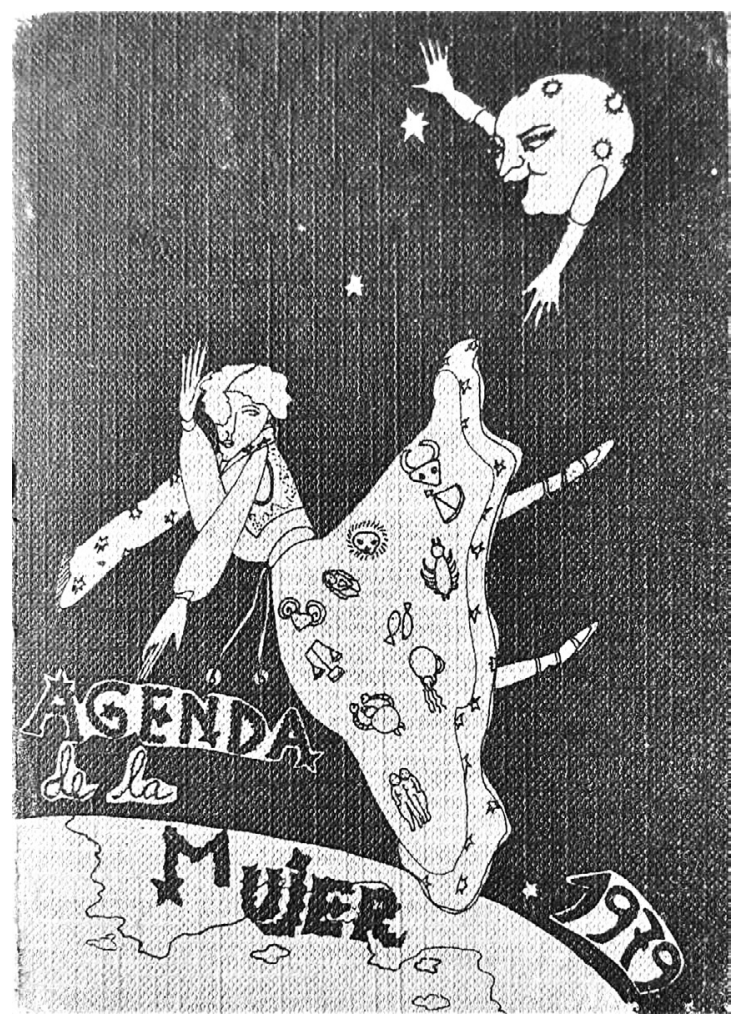

16 En afinidad con el situacionismo y también Carla Lonzi, historiadora del arte italiana que pasó a la militancia feminista y teorizó acerca de la destrucción de la división entre arte/creatividad. 
rreras de un sistema del arte rígido, que mercantiliza el objeto de creación y lo convierte en fetiche. A pesar de eso, hoy sabemos, y la exposición Genealogías Feministas en el arte español $1960-2010^{17}$ ha sido fundamental en tal sentido, que su pintura, considerando la primera parte de su producción, se inscribe en el marco de las experiencias internacionales artísticas que han trabajando sobre el icono vaginal, ocupando un puesto importante entre las pioneras. En la serie Vaginal, realizada a partir de 1966, podemos observar formas convexas, sinuosas, pintadas con extensas áreas de colores monocromos, vivaces, que dan la sensación de movimientos lentos, de aperturas, que aluden a los genitales femeninos. Chordà abre sin saberlo esta ola de subversión, tratando de manera original este tema, empezando por una búsqueda interior, realizando los que podríamos llamar autorretratos interiores, y entra en diálogo con muchas artistas del mundo que trabajaron en la misma trayectoria como Judy Chicago, Miriam Shapiro, Suzanne Santoro. Chordà, en principio autónomamente y luego con LaSal, publicó también productos artísticos únicos, elegantes, entre la poesía y la novela gráfica, como fueron I Moltes Altres coses y Quadern del cos i I'aigua (con ilustraciones de Montserrat Clavé).

En 1978 en LaSal se proyecta Boy meets Girl, vídeo de la artista catalana Eugènia Balcells, y que desde unos años ha sido insertada en la sala "Revolución Feminista" del Museo Nacional Centro de Arte Reina Sofía. Boy meets Girl es una película rodada en $8 \mathrm{~mm}$, de 10 minutos de duración ${ }^{18}$, montada según dos registros verticales, de manera que dé la sensación de ser una máquina tragaperras, con imágenes de mujeres en la parte izquierda y de hombres en la derecha. Analizando las imágenes y el momento en que se paran en ambos lados, se pueden ver mujeres que casi siempre están semidesnudas, inmóviles, seductoras, guapas, jóvenes y, en muchos casos, son modelos anónimos dentro de un espacio cerrado, como si fuese un set o el espacio doméstico. En el lado derecho se ve al hombre, generalmente maduro, sabio o joven viril, en lugares abiertos, a caballo, en moto, en coche, tocando instrumentos musicales, en traje militar o hasta preparándose para llegar a la Luna. La mujer se inscribe dentro del ideal refugio erótico, entre la pasividad y la hermosura, mientras el hombre transmite solidez intelectual, acción y libertad. Sin embargo, la operación de Balcells va más allá de denunciar lo que simplemente es la discriminación que

17 Se hace referencia a la exposición Genealogías Feministas en el arte español 1960-2010, comisariada por Patricia Mayayo y Juan Vicente Aliaga en León, Museo de Arte Contemporáneo de Castilla y León, desde el 23 de junio de 2012 hasta el 24 de febrero de 2013.

18 El vídeo posteriormente pasará a 16 minutos en Nueva York. 
ejerce la sociedad, el mensaje es más complejo. Como afirma Griselda Pollock, muchas prácticas de mujeres artistas no se limitan a reproducir el mundo, sino que accionan su definición, construcción y redefinición ${ }^{19}$. Balcells, a través de una repetición obsesiva y momentos de rotura, genera una desestructuración de la imagen/vídeo símbolo de una rotura de la identidad y asume un rol precursor de muchas prácticas artísticas feministas que, en la década siguiente, trabajarán la identidad bajo una perspectiva postmoderna (multiplicación, repetición, desestructuración). La idea que transmite el vídeo, además, en su reproducción de tópicos, fórmulas estereotipadas de roles, sugiere una actuación de las personas, como papeles preconstituidos, a través de la repetición compulsiva de modelos, en un mecanismo de pura actuación y reproducción tantas veces repetido hasta parecer algo natural ${ }^{20}$.

La producción artística "expandida" de LaSal vino en cambio de la mano de Montserrat Clavé, Elsa Plaza y Núria Pompeia. La revolución de sus ilustraciones cabe en un discurso más amplio dentro de la tradición de la ilustración y de la historieta. Estas ilustradoras eran profesionales que a la vez trabajaron en el cómic político, underground y marginal de los setenta. La aparición del cómic feminista en España, de hecho, se adscribe a las revistas comprometidas políticamente y a las de militancia feminista. Las ilustradoras trabajaron para revolucionar el rol de la mujer que, por primera vez, sale del estereotipo que la veía como una subalterna, un personaje silenciado o un objeto erótico para convertirse en compañera de lucha política del hombre. El personaje femenino del cómic de hecho, llegaba a los setenta, después de décadas bajo el franquismo, donde el tebeo femenino, diferente del tebeo para hombres, había constituido el tópico de la mujer como sujeto paciente y apto sólo para los trabajos domésticos y el cuidado de los hijos. Como señala Juan Antonio Ramírez, el género del tebeo femenino o rosa, creado para las chicas y las mujeres además representaba el mundo único de vida de las mujeres, no el momento de diversión en una vida activa, fomentando la desconexión de la realidad y la ensoñación, cuya «conse-

19 "Art is a part of social production; it is productive and actively produces meanings. Furthermore, art is constitutive of ideology, it does not merely illustrate it. It is one of the social practices through which particular views of the world, definitions and identities for us to live by, are constructed, reproduced, and even redefined» ( $\mathrm{El}$ arte es parte de la producción social; es productivo y produce activamente significados. Es más, el arte constituye la ideología, no se limita a ilustrarla. Es una de las prácticas sociales a través de las cuales se nos construyen, reproducen e incluso redefinen visiones particulares del mundo, definiciones e identidades con las que tenemos que vivir", POLLOCK, Griselda, "Women, Art, and Ideology: Questions for Feminist Art Historians", Women's Studies Quarterly, vol. 15, n. ${ }^{\circ}$ 1/2, Spring-Summer, 1987, p. 6.

20 Para esta interpretación se hace referencia a las teorías sobre la identidad preformativa en BUTLER, Judith, Gender Trouble: Feminism and the Subversion of Identity, Routledge, Nueva York-Londres, 1990. 
cuencia inmediata es la pasividad, la entrega sumisa a lo establecido ${ }^{21}$ (actitud que seguirá en las fotonovelas y telenovelas en las décadas siguientes). La subversión a este modelo se sitúa dentro de una ola de revolución del cómic, cuando en paralelo con la contracultura, el rock, el compromiso político, se desarrollan nuevos estilos narrativos y gráficos y, desde el punto de vista estilístico, se sale de los modelos tradicionales. La salida de los tópicos implicaba también cuerpos desnudos y una proliferación de nuevas libertades que coincidía con la época del "destape», pronto convertida en un mecanismo público y nuevo de humillación del sujeto femenino, "la libertad de prensa ha significado, para la mujer, ser tratada como una mercancía destinada a un mercado fetichista ${ }^{22}$.

Focalizándonos sobre las ilustradoras de LaSal, se trata de autoras que rompen la perpetuación del modelo conservador en el cual se habían criado, aquel tópico prefijado para garantizar el orden preexistente, creando tipologías narrativas ex novo, ya sea trabajando para LaSal o en general en el mundo de la ilustración.

Montserrat Clavé empezó a dibujar cómics clandestinos bajo el franquismo. Comprometida políticamente había participado en el Mayo francés y viajado a Cuba. Cuando en 1971 vuelve a Barcelona, empieza a comprometerse con la causa feminista y a la vez a trabajar como autora de cómic a nivel profesional. Trabajó para diferentes revistas como Butifarra, Trocha y Troya. Junto con otras firmas femeninas del momento, entre las cuales, Marika, empieza por primera vez en España a cuestionar la representación del sujeto femenino en el mundo de los tebeos. Con LaSal realizó las ilustraciones para la Agenda de la Dona y los dibujos de Quadern del cos i I'aigua con poesías de Mari Chordà, un libro de artista publicado por La Sal, Edicions de les Dones. Se trata de un cuaderno formato A4, que adquiere la forma de un diario, con poesías escritas a mano y montadas con dibujos, que narran la experiencia del descubrimiento sexual femenino. Con este trabajo, se escapaba del horizonte opresivo típico del momento, introduciendo elementos positivos y yendo más allá de una concepción dualística de la sexualidad, heteronormativa, representando un nuevo y posible placer para la mujer, aludiendo al agua y a una naturaleza cómplice con el despertar de la sexualidad, invocando, de manera sutil, una sexualidad diferente y lesbiana. Sobre el mismo argumento realizó la historieta $\mathrm{La} \mathrm{Mar}^{23}$, con textos

21 RAMÍREZ, Juan Antonio, El "cómic» femenino en España. Arte sub y anulación, Madrid, Edicusa, 1975, p. 189.

22 VIRGIL, Mariló, "Destape: ahora la mujer será vendida en preservativos de plástico», Vindicación Feminista, 1 diciembre 1976, p. 41.

23 Publicada en Tótem, Extra n. ${ }^{\circ}$ 2: Especial Mujer, 1978, Madrid, Editorial Fronteras, pp. 95-97. 
5. Montse Clavé, portada de Las Entrañablesas, cap. I, «Ni un siglo más»

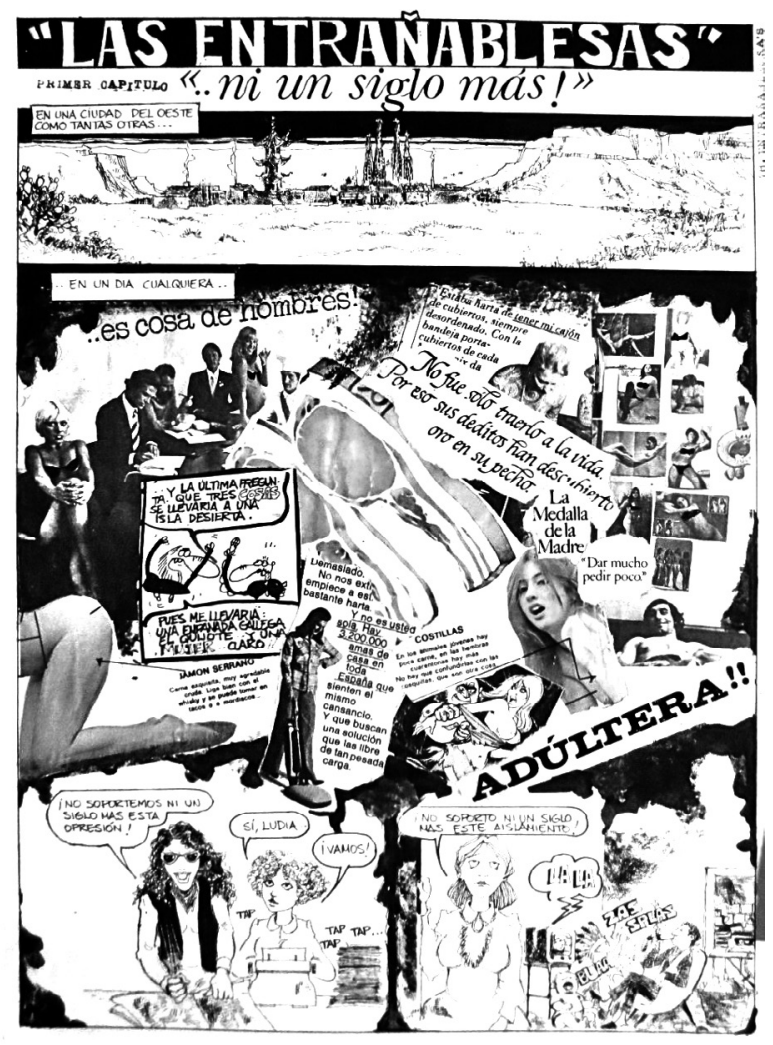




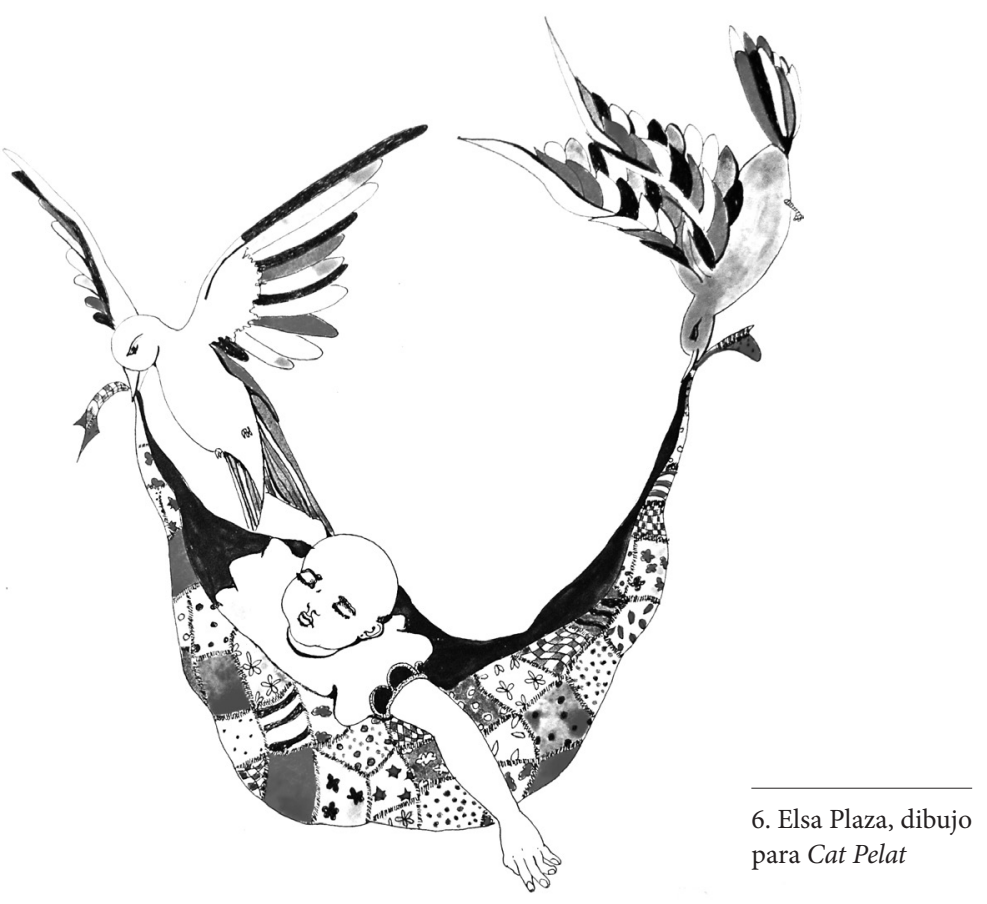

toconciencia. Gracias a Chordà entra en LaSal, abierta desde hacía ya tiempo, colabora como ilustradora y trabaja de voluntaria como camarera y cocinera para el espacio, donde además expuso una muestra de trabajos y colaboró en la realización de ilustraciones para eventos y para la Agenda de la Dona. Con LaSal Edicions de les Dones, publica también el cuento infantil Cap pelat, con textos de Ángela Lorente [6], donde se pretende salir del modelo de la fábulas tradicionales, para ahondar en el malestar debido a la presión sobre el aspecto físico (en este caso el pelo, del que carece la protagonista) construyendo un relato, con pocas y sencillas palabras, así como dibujos, en contra de la superficialidad. Con sus ilustraciones Plaza contribuyó a la construcción de un nuevo imaginario visual, representando temáticas que, por primera vez, se centraban en el mundo interior femenino. En los dibujos para la Agenda de la Mujer, Plaza trata temas que reflejan el feminismo tanto desde un punto de vista positivo, como la relación de hermandad entre mujeres, como desde una vertiente más dramática y compleja, como la relación entre madre e hija, la prostitución, la obsesión por la 


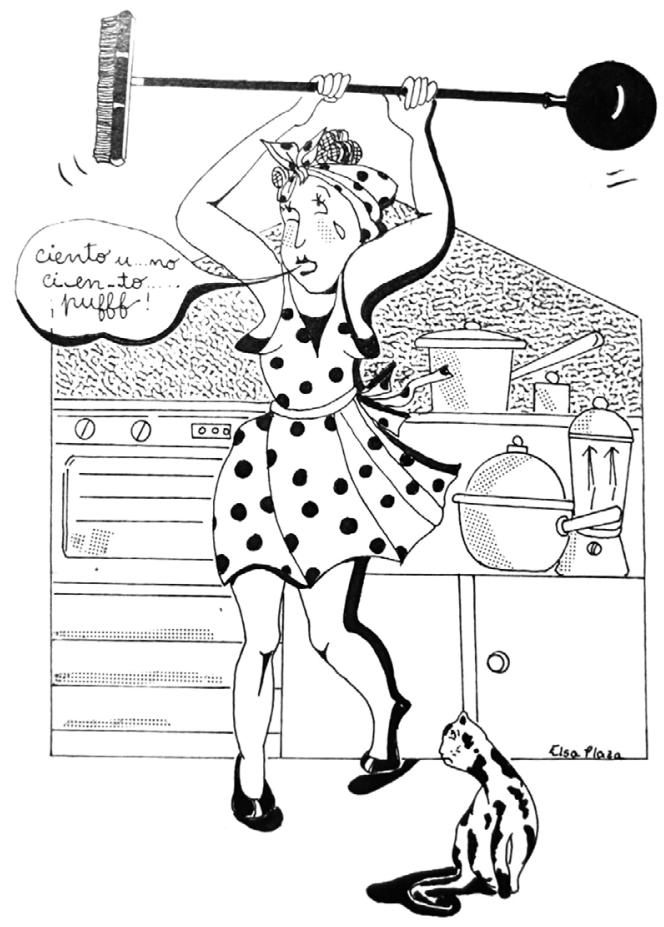

belleza influida por modelos publicitarios. Relacionado con el tema de la belleza sacó a la luz temas de los que no se hablaba mucho, como los trastornos alimenticios, en especial la bulimia, dibujados con amarga ironía [7].

Núria Pompeia nace en Barcelona, donde realiza estudios de arte. Se especializa en humor gráfico y se distingue por ser pionera en este género. Sus sátiras, desde los años sesenta, manifiestan irónicamente una denuncia a la burguesía y al machismo de la sociedad. Este aspecto será el elemento más característico de su trabajo, que es un reflejo de su tiempo, convirtiéndose en la ilustradora por excelencia del movimiento feminista en España, haciendo ilustraciones para los encuentros, los convenios o las revistas, sobre todo dibujando para Vindicación Feminista. Colabora en LaSal, para la Agenda de les Dones, donde trata sus temas habituales como la maternidad y la sexualidad, sobre los cuales realiza muchas viñetas divertidas y a la vez tristes, representando falsos mitos, cierto rechazo a la representación pornográfica y fetichista del cuerpo de la mujer, ingenuidades, lugares comunes y una gran autoironía sobre el mismo 
feminismo. En los mismos años publica varios libros de ilustraciones feministas como La educación de Palmira en 1972, Mujercitas en 1975 y El derecho a la contracepción. Los métodos anticonceptivos y sus indicaciones en 1978.

\section{LaSal, espacio heterotópico}

LaSal fue esencialmente un espacio liberado, uno de los diferentes lugares que se configuraron como heterotopías, conectados a todos los otros y a la vez transgresores de las costumbres relacionales y lingüísticas vigentes. Es imposible darse cuenta del valor del fenómeno si no hacemos un esfuerzo para comprender la situación dramática en que vivía la mujer: en los setenta todavía no podía salir libremente ni frecuentar bares o locales de ocio sin riesgos de ser atacada, a menos que no fuesen lugares dedicados al placer masculino. Para entender la importancia de un bar-biblioteca, debemos pensar que en las noches, en la mayor parte de los sitios, las mujeres eran rechazadas o juzgadas mal, atacadas o violadas, como afirma Plaza, "tradicionalment, I'espai bar és un espai amb fortes connotacions masculines on, en moltes ocasions, traspassar-ne el Ilindar és, per a nosaltres dones, una infracció a un codi, si bé no explícit, sí interioritzat a través de l'experiència " ${ }^{24}$. En LaSal, las mujeres podían acceder libremente sin tener una finalidad específica (asambleas sindicales, autoconciencia, etc.), podían hacer lo que normalmente estaba prohibido y que representaba el aspecto más revolucionario: recrearse libremente. La muerte de Franco en este sentido es fundamental: las mujeres, en paralelo a otros sujetos marginales y reprimidos bajo el franquismo, como los homosexuales, las lesbianas y los/las transexuales, se sentían libres de reapropiarse de los lugares, aunque los prejuicios continuaron durante años. Varios lugares diferentes respecto a la normas sociales se encontraban en el mismo momento como la Librería de Les Dones de Barcelona o El Casal de la Dona. Además, no muy lejos de LaSal, estaba la filmoteca, el Cine Pardó, el Teatro Diana, el Cine Cèntric, el Local Libertario y la Asociación de Vecinos, así como locales como el Copacabana, la Bodega Apolo, El Molino, la Bodega Bohemia y muchos otros.

24 "Tradicionalmente, un espacio bar es un espacio con fuertes connotaciones masculinas, donde, en muchas ocasiones, traspasar el umbral es, para nosotras mujeres, una infracción a un código si bien no explícito, interiorizado a través de la experiencia» (Traducción de la autora). PLAZA, Elsa, "La Sal, barbiblioteca feminista: un espai per a la utopia», 20 Anys de feminisme a Catalunya, Barcelona, Associació de Dones per a la Celebració dels 20 Anys de les Primeres Jornades Catalanes de la Dona, 1998, p. 280. 
Separarse era una de las soluciones a las que llegó el feminismo de los setenta en el ámbito social y artístico, a nivel internacional. El puro acto de separarse, sin embargo, y crear espacios para mujeres, con las mismas lógicas de los otros existentes, es limitativo, de hecho, sobre los posibles modelos de separación se encendieron vivaces debates. Entre las posiciones internacionales destaca Anne Marie Sauzeau Boetti, crítica de arte francesa naturalizada italiana, combativa voz feminista en el panorama italiano, para la cual el concepto de separación no debía ser entendido como la creación de espacios separados al estilo norteamericano, sino como una acción interior, un proceso de búsqueda dentro de sí misma, en el espacio profundo. La vía del separatismo aparecía en un sentido más bien inmaterial, utópico, dentro de cada mujer, y debería llevar a un nuevo espacio simbólico, otro, posiblemente libre de condicionamientos milenarios culturales ${ }^{25}$. Sin embargo Sauzeau apoyó la Cooperativa Beato Angélico en Roma. El modelo en que se desarrolla LaSal es diferente de otros de autogestión más conocidos, como Air Gallery de Nueva York (galería de arte con promoción artística) o como el menos conocido, la Cooperativa Beato Angelico de Roma (cooperativa, espacio artístico expositivo para las artistas). LaSal es un espacio poliédrico donde se deja también la posibilidad de acoger el discurso del arte, pero no únicamente, es una mezcla que recoge un potencial crítico y subversivo hacia el todo, y considerando el momento histórico, representa un impulso original y único en su género. Recordemos que en España, a diferencia de otros países como Estados Unidos o Italia -que desarrollaron un aparato teórico sobre arte y feminismo notable así como lugares de separación-, fenómenos de colectivismo antifranquistas en general absorbían, en muchos casos, las energías de las artistas feministas ya que era más urgente hacer frente común por un cambio total de la sociedad.

El no encajar con ejemplos tradicionales, nos lleva a una de las características originales de dicha experiencia: el aspecto revolucionario. La relación entre lo político y lo artístico es más estrecha que nunca. Según Hal Foster, precisamente las prácticas político/artísticas, junto a otros caminos, son precursoras de una actitud postmoderna de hacer arte político, en su paso de ser una representación del sujeto de clase (a la manera del realismo social) a hacer una crítica a los sistemas de representación social (su posicionamiento respecto al género, a los estereotipos étnicos, etc. $)^{26}$. La crítica contenida en las obras, entonces, no

25 SAUZEAU, Anne Marie, "Lo specchio ardente», Data, n. ${ }^{\circ} 18$, septiembre-octubre, 1975, p. 54. 
mira sólo el sistema de producción, sino al código cultural de representación ${ }^{27}$. Subrayar eso significa que cuando una artista trabaja sobre imágenes de la sociedad de masas que proponen y reproponen estereotipos negativos de la mujer, no está haciendo una simple representación de la realidad, sino que está subrayando la fuerza de los medios de comunicación en el consumo de los códigos, o sea, la perpetuación del sistema patriarcal. Además no circunscribir netamente el elemento artístico, es espejo del feminismo catalán radical, que ponía en duda el planteamiento general del saber.

Esta experiencia, como todas las revoluciones culturales, tiene cierta actitud iconoclasta y si por un lado fue importante para determinar un primer ejemplo de conexión entre la práctica creativa, curatorial y la política feminista en España, por el otro hay que reconocer también su valor por las especificidades inmateriales: el haber sido precursora de comportamientos del arte actual, que tendiendo más hacia la desaparición de lo material, se distinguen optando por el colectivismo, la participación, la relación.

27 Ibid., p. 99. 